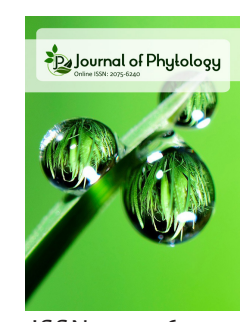

ISSN: $2075-6240$

\title{
Incidence of powdery mildew on Cucurbit plants in Katsina, Nigeria
}

\author{
Abubakar Umar Labo', Abrar Ahmad Khan² and Gufran Ahmad* \\ 'Department of Biology, Umaru Musa Yar’adua University, P.M.B.2218, Katsina, Nigeria, '2Department of Botany, \\ Aligarh MuslimUniversity, Aligarh, 202002, India
}

\begin{abstract}
The presence study deals with powdery mildews in various cucurbits in Katsina city (Barhim Estate, Kofar Durbi, Kofar Sauri, Kofar Marusa and Low Cost), Nigeria. The finding shows that the areas infested with powdery mildew is one of the important disease of cucurbits. The Sphaerotheca fuliginea was identified to be the causal organism present on all observed cucurbits in the study. Highest frequency of disease was found in Kofar Sauri $(79 \%)$ fallowed by Kofar Marusa (68\%), Kofar Durbi (66\%), Barhim Estate (65\%) and the lowest frequency of occurrence of disease was found in Low Cost (55\%). The intensity of the disease was moderate to severe in general but it was high in many fields, the area-wise variation was also noticed. On vegetables, the highest frequency of occurrence of powdery mildew disease was observed on L. cylindrica (76.4\%) followed by C. moschata (60\%), C. sativus (59.3\%), C. vulgaris (53.9\%) and lowest was found on C. melo (44.4\%). The highest intensity of disease was found on C. moschata, followed by L. cylindrica, C. sativus, C. vulgaris and C. melo.
\end{abstract}

Received: December 31, 2018

Accepted: January 28, 2019

*Corresponding Author:

Gufran Ahmad

Email: ahmadgufran811@gmail. com

KEYWORDS: Cucurbits, frequency, powdery mildew, S. Fuliginea, spore, symptoms

\section{INTRODUCTION}

Powdery mildew exists between such common, widespread and sometimes crop plants and ornaments that they are born on all crops every year in the growth of plants and crop, possibly due to the disease of another single type of plant Having crossed the losses. Powder mildews rarely kill their hosts, but use their nutrients, reduce photosynthesis, increase respiration and transpiration, inhibit their growth, and reduce yields, sometimes from 20-40\%. Plants which are most affected by powdered mildew mainly have different grains like wheat, barley, because in these crops, chemical control of plant disease is difficult. There are different crops which are under threat from powdery mildew like corky, especially kentalupa [1,2].

Powdery mildew is a common disease of cucurbitsunder fields and greenhouse conditions in most areas of the world. Although all cookutbits are susceptible, the symptoms are lower on cucumbers and watermelons because there is resistance in many commercial farms. This disease can be a major production problem. The amount of yield decreases due to any disease during the crop period. As a result of premature ejaculation of infected leaves, the quality of the market can be reduced because the fruits are burned before sunset or incomplete in the sun. In such fruits, the poor storage capacity (winter squash), the resultant soluble solids with the bad taste (watermelon), bad rind color (pumpkin), besides, powdery mildew infections specifically prefix the plants for other diseases. Saphathothaea Fulginand is the most common form of the ancient seepieri rim. Due to the powder fungal disease on fungus recorded cucurbits.

E. cichoracearum was considered to be the primary contingent organism around the world before 1958. Today S. Fulginnia is more commonly found [3]. Powder crystalline disease is caused by many different species of fungi. This is one of the easiest diseases to spot, because its symptoms are quite specific. The infected plants show white powder spots on the leaves and stems. The lower leaves or young leaves are most affected, but mildew can be seen on any upper part of the plant. As the disease progresses, the spots become larger and a large number of asexual spores are formed, and with high humidity and moderate temperature $[4,3]$, the mold increases well in the environment.

The cucurbits belong to family Cucurbitaceae. They are commonly grown in Nigeria which include Luffa cylindrica, Cucumis sativus, Cucumis melo, Citrullus vulgaris and Cucurbita moschata.Powdery mildew disease is very common on these cucurbits.In Nigeria, no work has been done so for on powdery mildew diseases, more especially in Northern Nigeria. However, the powdery mildew diseases are very common wherever 


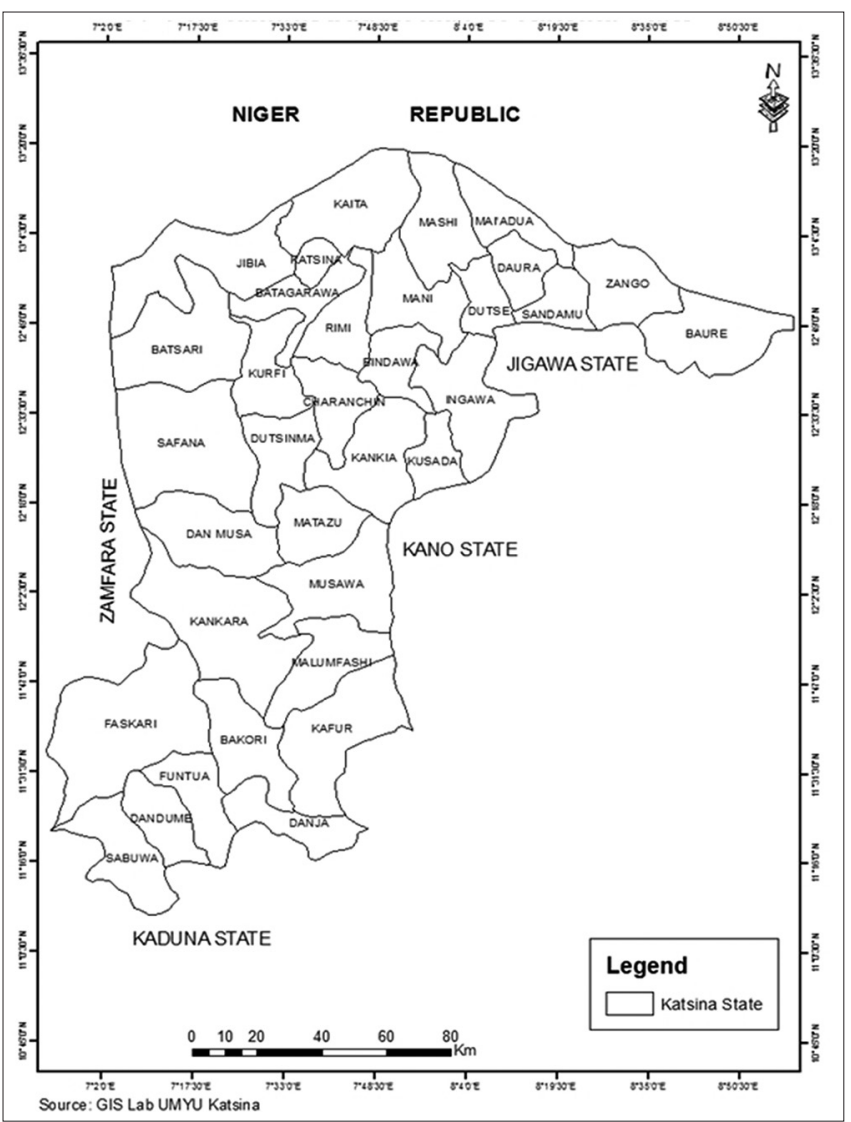

Adminstration map of Katsina state

cucurbitaceous crops are grown. For first time an aim was made to observe the incidence and intensity of disease and identify the species of powdery mildew on cucurbitaceous crops

\section{MATERIALS AND METHODS}

The following materials were used for present proposed study. The materials were as hand globs, needles, brush, white polythene bags, knife/blade, cover slip, binocular, light microscope, distilled water, $\mathrm{KOH}$ solution, cotton blue and ocular micrometer.

\section{Survey}

A detailed survey was conducted for powdery mildews on cucurbits in and around Katsina from September to November, 2015. Five cucurbits growing areas were selected in Katsina, which included Kofar Sauri, Kofar Durbi, Barhim Estate, Kofar Marusa and Low Cost.

(Figure $1 \& 2$ ) to observe the presence of the powdery mildew and to identify the species infecting cucurbits. The sporadic method was followed for the sampling of cucurbits in the survey.

\section{Pathogen: Sphaerotheca fuliginea}

Five samples from each cucurbits as Cucumis sativus (cucumber), Luffacylindrica (sponge gourd), Cucurbitamoschata

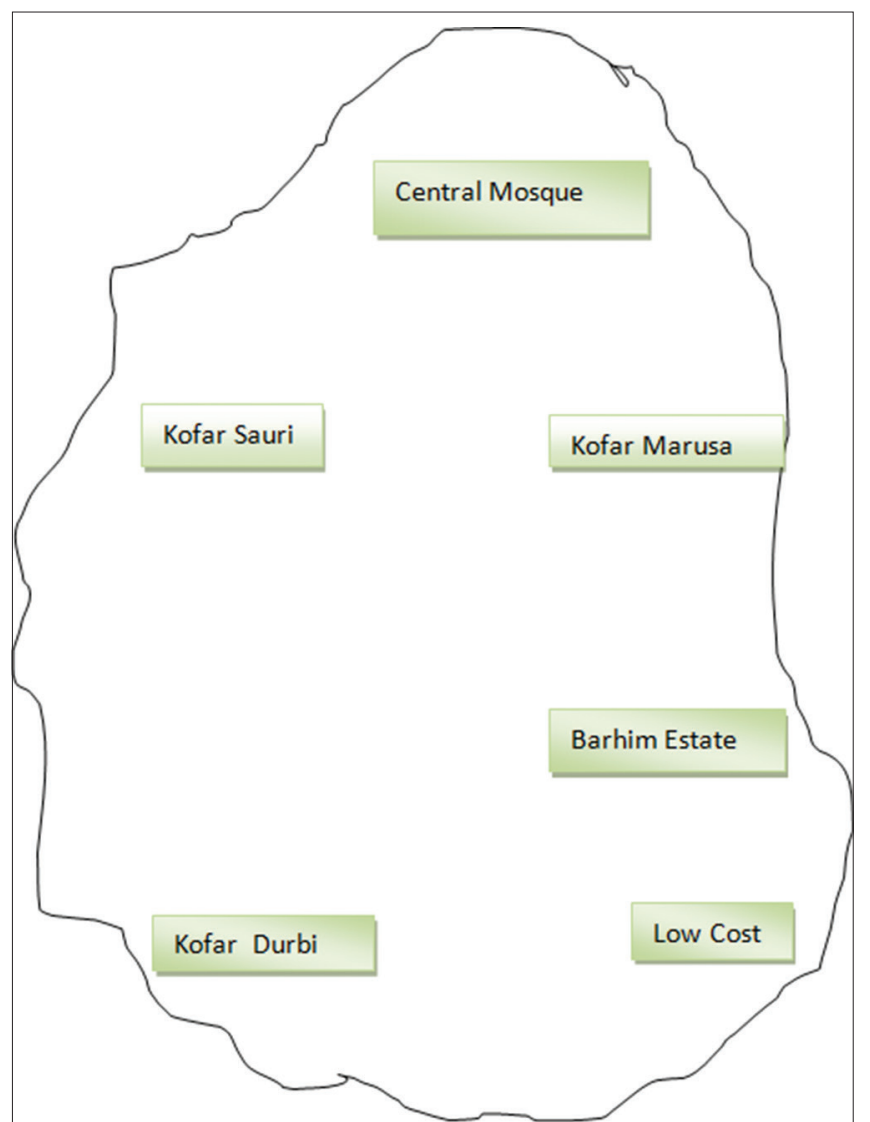

Figure 1: Showing the occurrence of powdery mildew in different localities of Katsina city

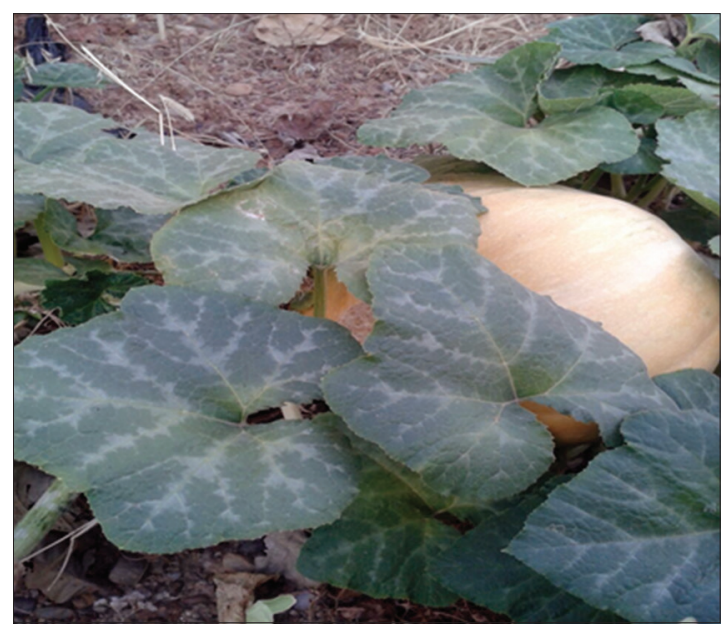

Figure 2: Showing infection of powdery mildew disease on Cucurbita moschata

(pumpkins), Citrullusvulgaris (water melon) and Cucumis melo (gurii) were collected in polythene bags separately and brought to the laboratory for detailed study under light micro scope. Samples of each cucurbit were collected at random from each available field/plot in Katsina. Cucurbits grown in kitchen gardens, farm yards, orchards or climbing on roof - tops or huts or other dwelling units were also included for sampling. Aerial parts of the plants (leaves, twigs, stem portions) were collected. 


\section{Laboratory Examination}

Infected leaves were selected for examination. Clean slide was used for microscopic examination. The spores from leaf were transferred on slide with the help of brush. A drop of water was put on the middle of slide. Very small cotton blue was used with the help of needle. Then cover slip was placed and observed under microscope. The species of powdery was identified on the basis of shape and size of spores. For conidial dimensions many slides prepared from each sample were measured with the help of ocular micrometer. L/B index was determined by dividing length of a conidium with it breath. Mean values and standard deviation were calculated.

\section{Incidence of Disease}

Incidence of disease (percent occurrence) on each cucurbit crop in an area was calculated as follows:

$$
\text { Disease incidence }(\%)=\frac{\begin{array}{l}
\text { Number of fields of cucurbit } \\
\text { with infection }
\end{array}}{\begin{array}{l}
\text { Total fields of cucurbit } \\
\text { surveyed }
\end{array}} \times 100
$$

\section{Intensity of Disease}

Severity (intensity) of the disease on crops and in different areas of Katsina was rated on $0-3$ scale as follows:

Grades: $0=$ No infection $(-)=$ No visible disease symptoms

$1=$ Mild infection $(+)=$ Pustules few, small in size and scattered

$2=$ Moderate $(++)=$ Pustules many, large in size tending to lesce, and

$3=$ Severe infection $(+++)=$ Large pustules covering almost the entire leaf areas.

Average of the ratings from different fields of Katsina was assigned as severity grades to each cucurbit in the areas.

\section{RESULTS}

The incidence of the powdery mildews diseases in terms of frequency of occurrence on different cucurbit crops for each locality of Katsina city are given in table 1 . The frequency of occurrence of the disease was high in field of Kofar Sauri (79.3\%) followed by Kofar Marusa (68.4\%), Kofar Durbi (66.6\%),Barhim Estate (65.7\%) and lowest in Low Cost (55.8\%). The average frequency of occurrence of powdery mildew disease in Katsina was $58.8 \%$ (Table 1). The frequency of occurrence of powdery mildew disease on C. moschata (Figure 2)was found highest in Barhim Estate (66.6\%) and Kofar Sauri (66.6\%) followed by Kofar Durbi (60\%), Low Cost (57\%) and lowest found in Kofar Marusa (50\%). The frequency of disease on L. cylindrica (Figure 3) was found highest in Kofar Sauri and Kofar Marusa that was (100\%) and lowest found in Low Cost (50\%). OnC. sativus(Figure 4) frequency was highest in Barhim Estate and lowest recorded in Low Cost (62.5\%). Similarly the frequency of disease on C. vulgaris(Figure 5) and C. melo(Figure 6)was highest in Kofar Sauri locality while the lowest was recorded $(50 \%)$ and $(44.4 \%)$ for $C$. vulgaris in Kofar Marusa and C. melo in Low Cost respectively.

Among the cucurbits, the highest frequency of occurrence was found L.cylindrica in Kofar Sauri and Kofar Marusa that was (100\%) and lowest was recorded on C. melo from Low Cost (Table 1).

On the basis of shape and size of spores the species of powdery mildew was identified as Sphaerotheca fuliginea on the entire included cucurbit crops from all the localities of Katsina (Table 2). In the conidial dimensions of the powdery mildew, the length of the spores was largest (Figure 7) in Barhim Estate

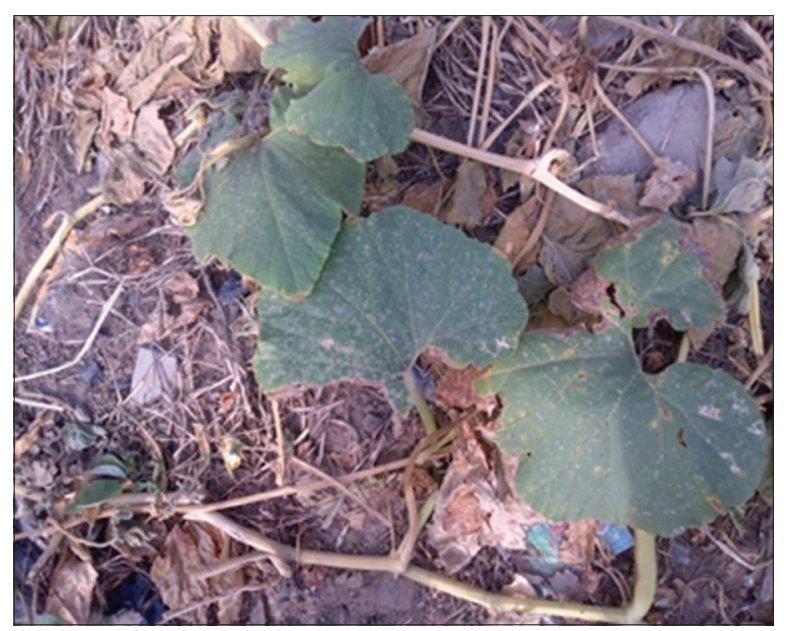

Figure 3: Showing infection of powdery mildew disease on Luffa

\begin{tabular}{|c|c|c|c|c|c|c|c|c|c|c|c|c|c|c|c|c|c|c|}
\hline \multirow[t]{3}{*}{ Cucurbits } & \multicolumn{18}{|c|}{ Localities } \\
\hline & \multicolumn{3}{|c|}{ Barhim estate } & \multicolumn{3}{|c|}{ Kofar Durbi } & \multicolumn{3}{|c|}{ Kofar sauri } & \multicolumn{3}{|c|}{ Kofar Marusa } & \multicolumn{3}{|c|}{ Low cost } & \multicolumn{3}{|c|}{ Total } \\
\hline & Sam & Inf & Freq & Sam & Inf & Freq & Sam & Inf & Freq & Sam & Inf & Freq & Sam & Inf & Freq & Sam & Inf & Freq \\
\hline C. moschata & 15 & 10 & 66.6 & 5 & 3 & 60.0 & 6 & 4 & 66.6 & 8 & 4 & 50 & 7 & 4 & 57.0 & 41 & 15 & 60.0 \\
\hline L. cylindrical & 7 & 4 & 57.4 & 8 & 6 & 75.0 & 4 & 4 & 100 & 7 & 7 & 100 & 6 & 3 & 50.0 & 32 & 24 & 76.4 \\
\hline C. sativus & 8 & 7 & 87.5 & 5 & 4 & 80.0 & 3 & 2 & 66.6 & - & - & - & 8 & 5 & 62.5 & 22 & 18 & 59.3 \\
\hline C. vulgaris & - & - & - & 7 & 4 & 57.4 & 8 & 7 & 87.5 & 4 & 4 & 50 & 4 & 3 & 75.0 & 23 & 16 & 53.9 \\
\hline C. melo & 8 & 4 & 50.0 & 8 & 5 & 62.5 & 8 & 6 & 75.5 & - & - & - & 9 & 4 & 44.4 & 33 & 19 & 44.4 \\
\hline Total & 38 & 25 & 65.7 & 33 & 22 & 66.6 & 9 & 23 & 79.3 & 19 & 13 & 68.4 & 34 & 19 & 55.8 & 151 & 92 & 58.8 \\
\hline
\end{tabular}
cylindrica

Table 1: Frequency of occurrence of powdery mildew on cucurbit crops in Katsina

Sam-Sample, Inf-Infected, Freq-Frequency 


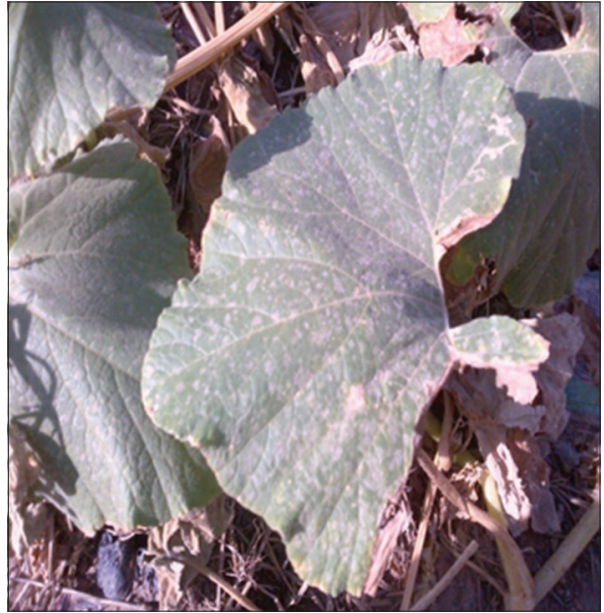

Figure 4: Showing infection of powdery mildew on Cucumis sativus

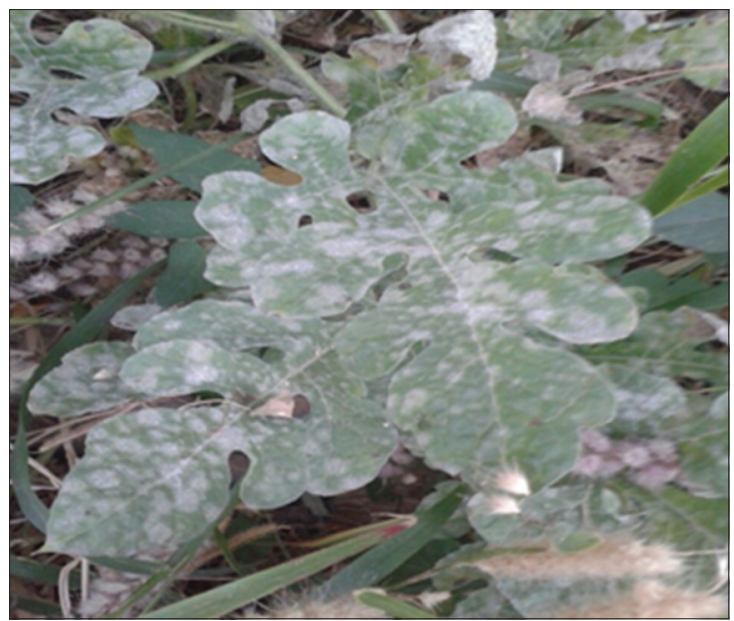

Figure 5: Showing the powdery mildew infection on Citrullus vulgaris

$(26.46 \mathrm{~cm})$ as well as the breath $(24.57 \mathrm{~cm})$ followed by Kofar Durbi, length $(23.52 \mathrm{~cm})$ and breath $(19.74 \mathrm{~cm})$; Low Cost, length $(22.70 \mathrm{~cm})$ and breath $(18.62 \mathrm{~cm})$ and smallest in Kofar Sauri, length $(17.03 \mathrm{~cm})$ and breath $(12.39 \mathrm{~cm})$. The L/B index of spores was found highest in Kofar Sauri (1.37) followed by Low Cost (1.21), Kofar Marusa (1.17), Kofar Durbi (1.14) and lowest in Barhim Estate (1.07) (Table 2).

The data presented in table 3 shows that severity of disease of powdery mildew was highest on C. moschata in Kofar Durbi $(+++)$, on L. cylindrical Barhim Estate and Low Cost, on C. sativus in Kofar Sauri, on C. vulgaris and C. melo on Kofar Marusa. The highest severity of diease of $\mathrm{S}$. fuliginea was observed in Kofar Marusa (11) and lowest was found in Low Cost (8). On cucurbits, the highest severity of disease was found on C. moschata (11) followed by L. cylindrical (10), C. sativus (10), C.vulgaris (9) and C. melo (9) (Table 3). Overall frequency of disease on severity grade was $49 \%$.

\section{DISCUSSION}

The study was conducted in some localities of Katsina city to assess the frequency of occurrence and intensity of the disease

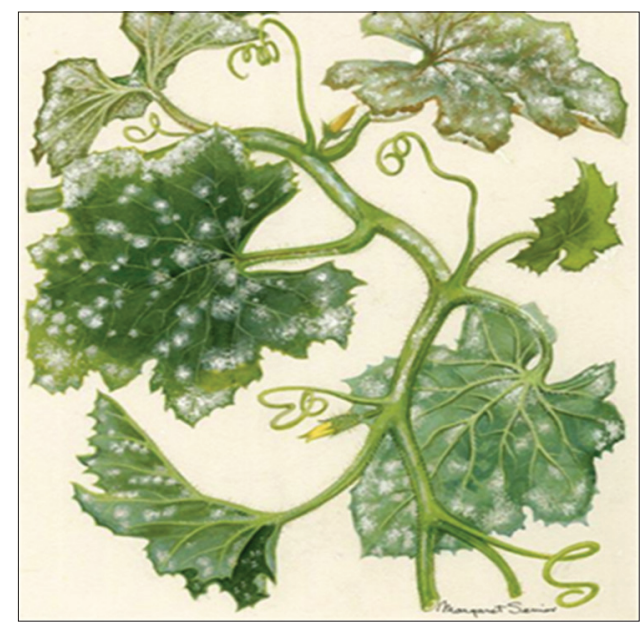

Figure 6: Showing infection of powdery mildew disease on Cucumis melo

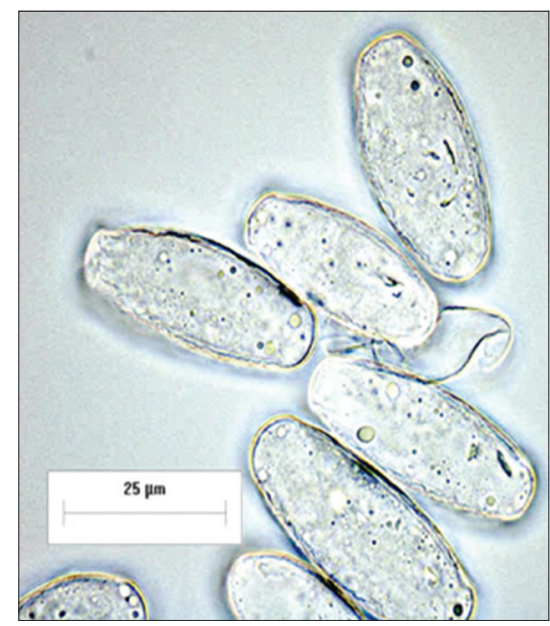

Figure 7: Showing the conidia of Sphaerotheca fuliginea with fibrosin bodies

Table 2: Conidial dimensions of powdery mildews on cucurbits collected from different localities of Katsina

\begin{tabular}{lcccc}
\hline Locality & Pathogen & \multicolumn{3}{c}{ Conidial dimension } \\
\cline { 3 - 5 } & & length (um) & Breath (um) & L/B index \\
\hline Barhim estate & S. fuliginea & $26.46 \pm 1.35$ & $24.57 \pm 23.37$ & 1.07 \\
Kofar Durbi & S. fuliginea & $23.52 \pm 4.20$ & $20.58 \pm 4.10$ & 1.14 \\
Kofar Sauri & S. fuliginea & $17.03 \pm 2.67$ & $12.39 \pm 0.29$ & 1.37 \\
Kofar Marusa & S. fuliginea & $23.10 \pm 2.14$ & $19.74 \pm 2.53$ & 1.17 \\
Low cost & S. fuliginea & $22.70 \pm 1.74$ & $18.62 \pm 2.62$ & 1.21 \\
Average & - & $22.56 \pm 17.1$ & $22.9 \pm 8.56$ & 1.19 \\
\hline
\end{tabular}

L/B index: length and breadth index Values are mean of 25 conidia; \pm standard deviation

caused by powdery mildew on cucurbit crops. The incidence in general was moderate to severe.Almost all cucurbits plants grown in the localities were found to be infected with powdery mildew disease in Katsina. S. fuliginea was identified to be responsible for powdery mildew disease on all cultivated cucurbits. However, severity of disease varied among the localities. Highest disease intensity was found on C. moschata and L.cylindrica. The frequency of occurrence was found to 
Table 3: Severity of powdery mildew disease on cucurbits in different localities of Katsina

\begin{tabular}{|c|c|c|c|c|c|c|}
\hline \multirow[t]{2}{*}{ Locality } & \multicolumn{5}{|c|}{ Vegetables } & \multirow[t]{2}{*}{ Total } \\
\hline & C.moschata & L cylindrical & C. sativus & C. vulgaris & C. melo & \\
\hline Barhim estate & ++ & +++ & ++ & ++ & + & 10 \\
\hline Kofar Durbi & +++ & + & ++ & ++ & ++ & 10 \\
\hline Kofar Sauri & ++ & ++ & +++ & + & ++ & 10 \\
\hline Kofar Marusa & ++ & +++ & +++ & +++ & & 11 \\
\hline Low cost & ++ & +++ & + & + & & 8 \\
\hline Total & 11 & 10 & 10 & 9 & 9 & 49 \\
\hline
\end{tabular}

Grade: $+=$ mild $;++=$ moderate $;++=$ severe $;-=$ No infection

be very high onL.cylindrica in Kofar Sauri and Kofar Marusa. Among localities, highest frequency of disease was found in Kofar Sauri and lowest was in Low Cost area.

S. fuliginea infects a large number of cucurbits all over the world in various agro climatic condition $[5,6,7,8]$. The $S$. fuliginea has already been reported on cucurbits in Libya and North African countries [9]. The present record of occurrence of S.fuliginea on cucurbits in Katsina (Northern Nigeria) is obvious as its climate is also similar to Libya and other sub Sahara countries. S. fuliginea may be a major pathogen causing powdery mildew of cucurbits in this relatively unexplored region: this, however, needs further detailed investigation.

\section{CONCLUSION}

This is the first report of $S$. fuliginea on cucurbits in Katsina state. The rate at which powdery mildews affect cucurbitaceae family members in present day has been an issue of a great concern to the farmers. The present observation demonstrated that the localities have sufficient infestation of powdery mildew disease. The occurrence of $S$. fuliginea in the localities is of great importance. The high infestation ensures high damage to the crops.

\section{REFERENCES}

1. Jhooty, J.S. Pathological specialization in S. fuliginea causing powdery mildew of cucurbits. Indian Phytopath. 1967,38: 302-305

2. Khan, M.W. Studies on powdery mildew resistance in cucurbits 1972, Report PL-480 Project, Aligarh Muslim University, Aligarh.

3. Khan, M.W. The identity of powdery mildew of cucurbits - a critical apparaisal.Acta. Bot. Indica. 1983,11: 97-126

4. Dave, G.S., Khosla, H.K. and Nema, K.G. Identity of powdery mildews of cucurbits-IJNKVV Res. J. 1971, 5: 133.

5. Ballantyne, B.J. Powdery mildew of cucurbitaceae: Identity distribution, host range and sources of resistance. Proc. Linn. Soc. New South Wales. 1975,99:100-120.

6. Khan, M.W. Powdery mildew of cucurbits- a three pathogen disease. Int. J. Trop. Plant. Dis. 1977, 107-123.

7. Sharma, A.K. Powdery mildew of some cucurbits from Jammu. Indian Phytopath. 1978,31: 85-86.

8. Ullasa, B.A. and Amin, K.S. Simultaneous occurrence of powdery mildews on Cucurbita maxima Dust and Abelmoschus esculantus (L.) Moench. from Karnataka, India. Curr. Sci.1981,50: 238.

9. El-Ammari, S.S. and Khan, M.W. Leveillula taurica powdery mildew on greenhouse cucumber in Lihya. Plant Disease 1983,67: 5-53 - 555 